\title{
INTRODUCCIÓN AL DERECHO PENAL DE LA COMPETENCIA. ANÁLISIS HISTÓRICO Y COMPARATIVO DEL DECRETO LEGISLATIVO 701
}

Manuel Abanto Vásquez

Hasta antes del 7 de noviembre de 1991 no existía en el Perú una ley contra las prácticas restrictivas de la competencia, ni tampoco un derecho de cárteles. En este sentido el legislador peruano se encontraba «atrasado» con respecto a las legislaciones de otros países con sistema de economía de mercado, que cuentan con una larga tradición de legislación antimonopólica, basada en una simple y lógica concepción de supervivencia: el Estado tiene que proteger al sistema económico de su autodestrucción, la cual podría ser generada por los propios operadores del mercado mediante restricciones a la competencia'.

Dicha protección de la libre competencia puede darse mediante prohibiciones administrativas y/o penales. Esto presupone, por un lado, la implementación de órganos administrativos idóneos y jueces penales especializados, dada la complejidad de la materia en cuestión. Por otro lado, una protección penal que no atente contra el principio de ultima ratio tiene que poder ser justificada desde el punto de vista de su practicabilidad y efectividad, así como de la dañosidad social de las conductas sancionadas².

Para los efectos que aquí nos interesan, nos limitaremos a una exposición histórica y a un análisis comparativo de la ley peruana de «defensa de

1 Véase en este sentido: Tiedemann, 1972, p. 59 ss.; 1976-A, p. 9 ss; Rittner, p. 113 ss.; Cabanellas, p. 35 . Un comentario más crítico se puede apreciar en Emmerich, p. 17 ss.

2 Detalladamente: Tiedemann, 1976-A, p. 95 y ss.; Geerds, p. 285 ss. 
la competencia». En cuanto a las cuestiones dogmáticas anteriormente aludidas, no nos queda más que remitir a la extensa literatura al respecto ${ }^{3}$.

\section{La legislación antimonopólica a través del tiempo}

Así, ya en 1892 se dio en los Estados Unidos la Sherman Act, destinada a impedir las prácticas antimonopólicas. Si bien en sus primeros años de vigencia esta ley no tuvo mayor significación práctica, posteriores modificaciones y la interpretación jurisprudencial mejoraron y desarrollaron el derecho antimonopólico norteamericano hasta convertirlo en el actual sistema, bastante elaborado, de influencia incuestionable en la legislación de muchos países ${ }^{4}$. También Francia está entre los países que introdujeron desde muy temprano una ley de protección de la competencia: la ley Chapelier apareció en 1791, es decir, prácticamente con la Revolución francesa, aunque aquí también la aplicación práctica se ha visto dificultada debido a problemas de técnica jurídicas.

En Alemania, el legislador, de oscilar entre políticas de cartelización y descartelización, condicionadas por el curso histórico de los acontecimientos en dicho país, se decidió finalmente por una activa política contra las prácticas restrictivas de la competencia e introdujo la ley correspondiente en $1957^{6}$.

En el mismo año se firmó el Tratado de Fundación de la Comunidad Económica Europea (también llamado Tratado de Roma) que contempla prohibiciones de determinados acuerdos que restringen la competencia (artículo 85) y de abusos de posiciones dominantes en el mercado (artículo 86).

En Latinoamérica, la corriente sancionadora de las prácticas

${ }^{3}$ Consúltese, entre otros: Tiedemann, 1972, 1976-A; Emmerich; Rittner; Cabanellas; Geerds.

4 Consúltese al respecto, en especial: Malamud Goti; Righi, p. 17 ss., 60 ss.; Tiedemann, 1978-B.

s Ibidem.

6 Para mayores detalles, véase: Rittner, p. 114 ss.; Tiedemann, 1976-B, p. 14 ss. 
antimonopólicas hizo su aparición ya en las primeras décadas del siglo veinte como consecuencia de la influencia norteamericana en esta parte del continente. Así, la primera ley antimonopólica argentina data de 1923. En los años sesenta y setenta se dieron leyes correspondientes en Brasil, Colombia y Chile. Es importante anotar aquí que el sistema sancionatorio norteamericano fue asumido por las leyes (penales) sudamericanas, en discordancia con el sistema penal ya existente en nuestros países, de clara tendencia continental?.

La ley peruana, entonces, no significa más que la consecuencia lógica de un sistema de economía de mercado, el cual, para que pueda ser eficiente y no se destruya a sí mismo, debe ser protegido legalmente.

Ahora bien, desde el punto de vista sistemático es preciso analizar primeramente los modelos existentes para poder, después, realizar el análisis comparativo de los tipos penales de la ley peruana y apreciar así en qué medida ella está en condiciones de proteger efectivamente la economía de mercado.

\section{Sistemas de legislación antimonopólica ${ }^{8}$}

\subsection{El sistema norteamericano}

Habíamos adelantado que fue el sistema norteamericano el que influyó primeramente en las legislaciones latinoamericanas. Si bien la Sherman Act contenía, al principio, disposiciones demasiado imprecisas, éstas fueron co-

7 Hendler, 1982-B, p. 1012; Righi, p. 33.

8 Hay que aclarar aquí que, conforme la práctica impuesta, debe entenderse por sinónimos los términos «legislación antimonopólica» y «legislación contra las prácticas restrictivas de la competencia», pese a que en esencia no significan lo mismo. La legislación antimonopólica norteamericana tiende más bien a reprimir los intentos de monopolización en general, mientras que la tradición europea sanciona determinadas figuras que no necesariamente van dirigidas inmediatamente a la monopolización de un mercado (discriminaciones, acuerdos sobre precios, recomendaciones, etc.) o que incluso presuponen que existe ya un monopolio o seudomonopolio (abuso de posición dominante en el mercado). 
rregidas con posterioridad, fundamentalmente por la jurisprudencia ${ }^{9}$. Este procedimiento es posible dentro del sistema anglosajón, pero no dentro del sistema jurídico latinoamericano, basado en el Derecho (penal) continental, que no puede permitir tanto espacio de actuación al juez. Éste sólo puede interpretar las leyes dadas previamente por el legislador. Tipos demasiado abiertos serían objetables desde el punto de vista de su constitucionalidad.

Es por eso que no puede recomendarse, en general, la adopción del sistema norteamericano. Una cuestión diferente consiste en lo que debe sancionarse (los tipos concretos) y cómo debe hacerse esto (mediante sanciones penales o sanciones administrativas, y qué tipo de sanción es la más adecuada). Sobre esto se tratará más adelante.

Por lo demás, la más reciente legislación antimonopólica sudamericana muestra una tendencia a alejarse del modelo de técnica jurídica norteamericana; tal es el caso de la ley argentina de defensa de la competencia 22.262 y de la reciente ley peruana ${ }^{10}$.

\subsection{El sistema alemán}

La ya mencionada ley de 1957 , «Ley contra las prácticas restrictivas de la competencia» (en adelante se le mencionará por sus siglas en alemán: GWB), surgió como un compromiso entre el gobierno federal y los sectores interesados de la economía. La planeada conminación penal de las conductas anticompetitivas tuvo que ceder a una simple conminación contravencional. Si bien algunos autores alemanes entienden el Derecho contravencional ${ }^{11}$ como un Derecho penal en sentido amplio, queda patente

9 La jurisprudencia norteamericana ha elaborado criterios que limitan la responsabilidad penal a aquellos casos en que las actuaciones antimonopólicas no obedecían a consideraciones razonables («rule of reason»). La «rule of reason» debe deducirse de los casos concretos. Véase Cabanellas, p. 76 ss.; Righi, p. 17 ss.

10 Véase la Exposición de Motivos de la ley argentina n. ${ }^{\circ} 22.262$ de 1980, en Cabanellas, p. 829 ss.; véase también Solsona, p. 800 ss.; Pedro Gutiérrez, p. 836 ss. En relación a los anteproyectos peruanos consúltese ILD, p. 87 ss.

"El Derecho contravencional alemán ha reemplazado a las faltas del Derecho penal. Constituye una auténtica rama del Derecho con una legislación propia que 
aquí la fuerza de los poderosos grupos económicos de interés para influir decisivamente en la legislación de un país ${ }^{12}$.

La GWB ha sufrido muchas críticas debido a su técnica extremadamente asistemática, e incluso confusa, que tiende a dificultar la previsibilidad en el destinatario de la norma (importante para la determinación de un error de prohibición). En cuanto a la efectividad de la protección del bien jurídico, hay opiniones contrarias en la doctrina alemana: unos verifican la ausencia de lagunas de protección, debido, a veces, a la sobreposición de tipos; otros se quejan, además de contra la ya mencionada falta de penalización de las acciones, de la carencia de determinadas figuras (p.e., estafa en las licitaciones), así como de la carencia de mayores posibilidades preventivas y represivas de las autoridades competentes (posibilidad de disolucion de cárteles) ${ }^{13}$.

Fundamentalmente la GWB alemana reprime la ejecución de acuerdos restrictivos de la competencia (p.e., acuerdos sobre precios, repartición de mercado), así como contactos similares entre competidores (p.e., recomendaciones, amenazas) y el abuso de una posición dominante en el mercado. Junto a estos tipos originarios se encuentran los tipos accesorios, que sancionan las acciones contrarias a disposiciones constitutivas de las autoridades (esto se da, p.e., en el campo del control de abusos o de las áreas de excepción), y los tipos de desobediencia, que garantizan las posibilidades de información de las autoridades, así como el cumplimiento de los deberes de proporcionar las informaciones ${ }^{14}$.

Finalmente hay que destacar que la ley conoce una serie de excepcio-

prevé sanciones, fundamentalmente multas, las cuales, a diferencia de las penales, no poseen carácter de «reproche social».

12 En contra de las recomendaciones de la comisión de expertos para la criminalización de determinadas prácticas anticompetitivas, aprovechando el proceso de reforma penal en 1975, esto no se llevó a cabo debido a la presión de grupos económicos que llegaron a provocar una crisis gubernamental al enfrentar al Ministerio de Justicia (a favor de la criminalización) con el Ministerio de Economía. Véase Tiedemann, 1985, p. 74; Dannecker, 1989, p. 672 ss.

13 Rittner, p. 136; críticamente véase Tiedemann, 1976-B, tomo II, p. 21.

14 Esta clasificación de los tipos de la GWB es propuesta por Tiedemann en: Tiedemann 1976-B, tomo II, p. 21. 
nes. Éstas pueden limitar la validez de la ley en determinados ramos de la economía (áreas de excepción) o pueden referirse a determinados casos concretos (p.e., cárteles de exportación o cárteles de rebaja). Muchas de estas excepciones han sido objeto de críticas, pues aquéllas no serían compatibles con el sentido y la finalidad de la ley desde el punto de vista del bien jurídico protegido, sino que obedecerían a simples reflexiones económicas ${ }^{15}$.

\subsection{El sistema de la Comunidad Europea}

E1 Tratado de la Comunidad Europea introdujo dos tipos amplios, conforme a la técnica francesa, contra las prácticas restrictivas de la competencia. El artículo 85 declara nulos y prohíbe ampliamente todos los acuerdos entre empresas, resoluciones de asociaciones de empresas y prácticas concertadas idóneos para dañar el comercio entre los Estados miembros (de la Comunidad), y que tengan por finalidad u ocasionen impedimento, limitación o falseamiento de la competencia dentro del Mercado Común. A esta prohibición general le sigue en el párrafo segundo una lista meramente ejemplificativa de cinco limitaciones de la competencia (fijaciones de precios; control o limitación de la producción, de la venta o del desarrollo técnico o de las inversiones; repartición de mercado o de fuentes de aprovisionamiento; discriminaciones, y negocios atados).

Por su parte el artículo 86 sanciona el aprovechamiento abusivo de una posición dominante en el mercado. La determinación de los conceptos utilizados, como, p.e., posición dominante en el mercado, se deja en manos de la práctica jurisprudencial. El sistema fue completado por la directiva n. ${ }^{\circ}$ 17 (dada en 1962), que introdujo el sistema de sanciones (fundamentalmente multas) y, considerando la seguridad jurídica en favor del empresario, la po-

15 Molsberger, p.e., está a favor de «una legislación de cárteles según el principio de prohibición», pero «con un ámbito de excepciones a la prohibición en lo posible mínimo, para no alentar la disponibilidad del operador particular a cometer restricciones a la competencia» (Molsberger, p. 195). La excepción de los cárteles de exportación es contradictoria y reprochable, en la medida en que se prohíben las restricciones a la competencia en el país, pero al mismo tiempo se les permite para que sean realizadas en el extranjero, e incluso a veces se les promueve. $C f r$. Tiedemann, 1989, p. 933 ss. 
sibilidad de que las autoridades comunitarias puedan repartir «certificados negativos» a petición de parte, que permitan a ésta saber por adelantado si la operación que quiere emprender se encuentra comprendida o no por las prohibiciones del Tratado.

Esta técnica de tipificación abierta fue escogida conscientemente, pues se consideró que la competencia, por ser un proceso dinámico, abierto al desarrollo, exige regulaciones legales que utilicen conceptos indeterminados. Además se tuvo en cuenta que el Tratado había sido concebido como «abierto al futuro», el cual tendría que ser modificado siguiendo pasos escalonados de integración ${ }^{16}$.

Gracias a este sistema las autoridades de cárteles de la C.E. han podido desarrollar libremente una política de control de cárteles bastante efectiva. Por un lado, conceden una mayor preferencia a la prevención frente a la represión. Por otro lado, los tipos abiertos han posibilitado una jurisprudencia bastante rica y creativa. Los peligros de una punibilidad indiscriminada debido a los tipos abiertos han sido eliminados mediante la reducción teleológica de la aplicación de los tipos a aquellas infracciones «sensibles». El «efecto sensible» (Spürbarkeit) se fija teniendo en cuenta criterios cuantitativos (comprobación de la idoneidad para un daño al comercio) y cualitativos (consideración de los daños que el autor pretendía o causó) ${ }^{17}$.

Además de que el sistema de la C.E. contempla las criticadas excepciones para los cárteles de exportación, su carácter supranacional impide a veces una adecuada sanción de los ilícitos. El hecho de que los países miembros tengan distintos sistemas penales (compárense, p.e., el sistema anglosajón y el sistema continental de Alemania) ha motivado que se exija una «armonización» de la persecución penal y de la aplicación de la pena. Esto parece por ahora irrealizable. Para cubrir las deficiencias se recomienda por ello, más bien, la introducción de una cláusula que sancione el fraude

\footnotetext{
16 Dannecker / Fischer-Fritsch, p. 28 ss.

17 Dannecker / Fischer-Fritsch, p. 15 ss. Véase también Rittner, p. 231 ss.
} 
de la ley ${ }^{18}$ y que se reconozca la potestad sancionatoria penal supranacional de la C.E. ${ }^{19}$.

\subsection{Los sistemas latinoamericanos}

Particularmente interesante, para nuestros fines, son las legislaciones antimonopólicas de Argentina y de Chile.

El sistema chileno aparece en la práctica como mucho más efectivo que el argentino, sobre todo si se considera que el primero ha producido una amplia e interesante jurisprudencia, mientras que el segundo rara vez ha sido aplicado. Sin embargo, los tipos chilenos, extremadamente abiertos, generan mayores reservas desde el punto de vista constitucional que los argentinos, mucho más detallados y precisos.

\subsubsection{La ley argentina de «defensa de la competencia»}

La ley 20.262 significó en su tiempo un gran cambio en el Derecho de cárteles argentino, porque introducía una nueva concepción en la lucha contra las prácticas restrictivas de la competencia: el abandono de los presupuestos de una competencia perfecta para, consecuentemente, tender a controlar ya no el simple poder económico, sino su aprovechamiento abusivo ${ }^{20}$.

18 La ausencia de esta cláusula permite muchos fraudes, sobre todo cuando se basan en disposiciones demasiado precisas de la C.E. Así, cuando, según las disposiciones de la C.E., se hace merecedora a un reintegro a la exportación la empresa que exporta salchichas, no se dice al mismo tiempo que éstas sean aptas para el consumo humano; por lo cual la exportación de deshechos de carne con forma de salchichas serían merecedoras del beneficio. Este caso se dio efectivamente en la práctica, y las autoridades de la C.E. se vieron obligadas a precisar en las disposiciones lo que debía entenderse por «salchichas» (que sean adecuadas para la alimentación humana); vid. Tiedemann, 1992, p. 116.

19 La C.E. no puede imponer sanciones penales, porque ni cuando se firmó el Tratado de Roma, ni después, se hizo un traslado expreso de soberanía para tal efecto. Vid. Tiedemann 1990.

20 Vid. Fargosi / Stiglitz; también Solsona, p. 801. 
La ley argentina conoce dos instancias sancionadoras, según la gravedad de la infracción. La autoridad administrativa se encarga de sancionar aquellas conductas tipificadas ampliamente en el artículo 1 de la ley (acuerdos restrictivos y abusos de posición dominante en el mercado), mientras que la autoridad penal reprime solamente las infracciones (dolosas) especificadas en los once tipos del artículo 41.

El primer gran problema con el que tropieza la persecución penal (y administrativa) de los ilícitos contra la competencia es el de la comprobación de la lesión al bien jurídico. Puesto que los tipos penales del artículo 41 constituyen una agravación con respecto al artículo 1, también los elementos típicos de éste forman parte de los de aquél ${ }^{21}$. Precisamente el tipo genérico del artículo 1 exige que se compruebe el peligro de una lesión al interés económico general («... de modo que pueda resultar perjuicio para el interés económico general»); es decir, se trataría de un peligro concreto, tal como lo ha interpretado la doctrina argentina ${ }^{22}$. La introducción de este nuevo bien jurídico en el Derecho de cárteles argentino, sin embargo, ha sido duramente criticada por la doctrina, ya que trae consigo problemas casi insuperables.

La exposición de motivos califica este hecho como un adelanto con respecto a la legislación anterior, la cual se refería únicamente a la competencia. La fundamentación de este cambio radicaría en que ahora «se hace referencia a un peligro concreto razonablemente determinable en cada caso particular y no a la mera posibilidad lógica y abstracta de lesión; y (además) con la afectación del interés económico general se deja en claro que es él el que sufre al trabarse el funcionamiento de un mercado, de suerte que quedan a salvo las conductas que puedan parecer anticompetitivas, pero que en verdad resultan beneficiosas para la comunidad ${ }^{23}$. Tal vez el cambio de denominación del bien jurídico no hubiera traído mayores problemas si al mismo tiempo se hubiera permanecido dentro del marco del peligro abstracto. Pero, al haberse introducido un tipo de peligro concreto se requiere ahora la

21 Esto no solamente se desprende del propio texto del artículo 41: «siempre que (los tipos penales) encuadren en el artículo l», sino que también lo acepta la doctrina argentina.

22 Cabanellas, p. 186 ss.; Solsona, p. 801 ss.

23 Exposición de Motivos, en Cabanellas, p. 830. 
verificación de la existencia de tal peligro para el bien jurídico, el cual además es muchísimo más impreciso. Si se considera que el interés económico general se vería ya afectado cuando las acciones crean el peligro de que la producción disminuya ${ }^{24}$, no solamente seguiría sin definirse lo que es el «interés económico general», sino que tampoco sería fácil comprobar dicha situación de peligro: el proceso se vería recargado con una serie de interminables y complicadas pericias.

La jurisprudencia ha tratado de precisar este concepto identificándolo con las mejores condiciones de competencia ${ }^{25}$; sin embargo, sin bien esta nueva concepción del interés económico general hace de éste un concepto más preciso y practicable, significa al mismo tiempo, también, un retorno a la concepción de la ley anterior (la libre competencia) que expresamente se quería reemplazar con el nuevo texto.

Otra crítica resalta el hecho de que los tipos penales del artículo 41 casi no se refieren a los casos (más graves) de abuso de posición dominante en el mercado. Puesto que casi todos los tipos del artículo 41 requieren que se cometan en el marco de acuerdos o acciones concertadas ${ }^{26}$ (que presuponen la ausencia de imposiciones abusivas). Únicamente el tipo de la imposición de condiciones contractuales daría cabida a casos punibles de abuso de posición dominante en el mercado ${ }^{27}$. Otros casos solamente podrían hacerse merecedores a sanciones administrativas en el marco del artículo 1.

Aparte de otras imprecisiones en los conceptos definidos, sobre todo para los casos de abuso de posición dominante ${ }^{28}$, la ley argentina presenta notorios vacíos. Entre éstos cuentan la ausencia de un tipo especial sobre estafa en las licitaciones, y una adecuada tipificación del dumping (oferta de

24 Malamud Goti, p. 55 ss.

25 Otamendi, p. 757.

26 Malamud Goti diferencia los «acuerdos» de las «acciones concertadas», considerando que los segundos se refieren a empresas con diferente posición en el mercado. De esta manera interpreta sistemáticamente los tipos del artículo 41 y admite más casos de abuso de posición dominante que el resto de la doctrina (Malamud Goti, p. 60, 61 ss.). La mayoría de los autores equipara, sin embargo, ambos conceptos; por todos Hendler, 1981, p. 1018.

27 Cabanellas, p. 675; Hendler, 1982-B, p. 1024.

28 Detalladamente, véase Hendler, 1982-B, p. 1024. 
precios por debajo del costo con fines anticompetitivos). Sobre el primero, la dación de un tipo penal especial se hace necesaria porque el tipo general de la estafa fracasa en este caso, ya que no es verificable el daño al patrimonio de la víctima ${ }^{29}$. En cuanto al dumping, si bien éste, según la exposición de motivos, se encuentra considerado expresamente en el sexto supuesto del artículo 41, su descripción es incompleta y se refiere a los casos menos frecuentes de impedimentos a la entrada al mercado de competidores. Más común es que sea precisamente una sola empresa poderosa quien mediante precios por debajo de costo trate de eliminar del mercado a otra empresa ${ }^{30}$. Por lo visto la jurisprudencia argentina es también de este parecer, pues solamente subsume estos casos de dumping dentro del artículo 1 (es decir, como ilícito administrativo), pero exige que el resultado dañoso (la expulsión o impedimento de entrada al mercado) se haya producido ${ }^{31}$.

\subsubsection{El decreto ley 211 chileno}

En el marco de la dictadura de Pinochet se introdujo en Chile una fuerte concepción liberal de la economía, para cuya protección se promulgaron, en 1973, las «Normas para la defensa de la libre competencia», D.L. 211, las que fueron modificadas después por el D.L. 2.760 de 1979.

Sin embargo, desde el punto de vista de las garantías penales, la técnica empleada resulta muy deficiente, ya que los tipos legales son demasiado abiertos, imprecisos. Así, el artículo 1 sanciona con presidio menor a quien «ejecute o celebre individual o colectivamente cualquier hecho, acto o convención que tienda a impedir la libre competencia en la producción o en el comercio interno o externo». A continuación, el artículo 2 presenta una lista de conductas que se considera que atentan contra la libre competencia, pero que solamente tienen carácter ejemplificativo, pues el último inciso extiende la punición a «cualquier otro arbitrio que tenga por finalidad eliminar, restringir o entorpecer la libre competencia» (artículo 2, lit. f).

29 Así lo reconoce la actual doctrina alemana. Consúltese, entre otros: Baumann, p. 291 ss.; Joecks, p. 247.

30 Malamud Goti, p. 88 ss.

31 Sobre esto véase Otamendi, p. 764; Maas, p. 944 ss. 
Pese a las evidentes insuficiencias jurídicas de la ley, que incluso han generado críticas en contra de su constitucionalidad, la «Comisión Resolutiva» chilena (órgano sancionador administrativo) ha desarrollado criterios jurisprudenciales que han logrado concretar los presupuestos legales. Así, p.e., ha considerado como bien jurídico protegido a la competencia misma, la cual se vería lesionada al ser restringida, sin necesidad de comprobar un daño en el mercado ${ }^{32}$.

La reforma de 1976 introdujo el concepto de «abuso de posiciones monopólicas» (artículo 8, lit. c y d del texto modificado), provenientes de monopolios naturales o estatales ${ }^{33}$, con lo cual se ha precisado más el texto amplio de los tipos de la ley.

La ley considera también medidas preventivas. Tal es el caso de la posibilidad de absolver consultas a petición de las empresas, consultas que sirven como certificados negativos en caso de que se abra proceso por la conducta considerada en aquéllas conforme a ley. Si la jurisprudencia modifica sus criterios, no puede imponer sanciones al consultante, pero puede exigirle el cese de la acción emprendida. Este sistema ha demostrado y revelado ser muy eficaz ${ }^{34}$.

La Comisión Resolutiva ha ganado tal prestigio en la resolución de los casos, que casi todas las sentencias recurridas ante la Corte Suprema en vía de apelación o de queja son confirmadas.

Ciertamente la redacción de la ley chilena no puede cumplir con las exigencias rígidas de un Estado de Derecho ${ }^{35}$, pero tampoco se puede desco-

32 Malamud Goti, pp. 57, 72.

33 En la práctica la Comisión Resolutiva ha impuesto sanciones por casos de abuso de posiciones monopólicas: la empresa eléctrica Chilectra S.A. trató varias veces de cobrar una deuda inexistente a un usuario sin dar aclaraciones satisfactorias y amenazando interrumpir el servicio; RDJyGT, 1987-II, p. 39 ss. En otro caso, los administradores de una terminal de autobuses en Vallenar introdujeron el cobro de un derecho adicional que tenían que abonar los viajeros para ingresar al andén respectivo; RDJyGT, 1987-II, p. 72 ss.

34 Entre 1973 y 1989 se absolvieron más de 700 consultas; comp. Ortúzar Latapiat, p. 21 ss.

35. Malamud Goti comprueba que la Comisión Resolutiva tiene especial predilec- 
nocer que el sistema chileno es quizás el más efectivo de Latinoamérica. Esto corroboraría la observación de Tiedemann, en el sentido de que la actuación efectiva de autoridades capaces muchas veces puede conseguir más, que leyes complicadas y exactas ${ }^{36}$.

\section{El nuevo Derecho de monopolios peruano}

Ya la Constitución peruana de 1933 preveía una declaración general de prohibición de monopolios. La Constitución de 1979 ha resaltado el mismo principio, incluso de manera más notoria: el artículo 115 establece la economía social de mercado como ordenamiento economico peruano. El artículo 133 prohíbe expresamente los monopolios, oligopolios, acaparamientos y prácticas y acuerdos restrictivos en la actividad industrial y mercantil, encargándose a una futura ley la tarea de regular la normal actividad del mercado y de establecer las sanciones correspondientes*.

Desde la vigencia de la Constitución, sin embargo, no se consideró la necesidad de la dación de una ley contra las prácticas restrictivas de la competencia. Los gobiernos sucesivos solamente se contentaron con expedir leyes contra la especulación y acaparamiento, en un marco de política económica de control de precios (contrario por definición a un sistema de libre oferta y demanda).

La política económica peruana ha cambiado continuamente de orientación, sin que se haya erigido alguna vez una auténtica economía de mercado. Sea durante las dictaduras o durante gobiernos democráticamente elegidos, siempre se tendía a favorecer a determinado grupo de empresas nacionales y extranjeras ${ }^{37}$.

ción por la utilización de la cláusula abierta del artículo 2 , lit. f ya mencionada («cualquier otro arbitrio»), que le permite comprender prácticas no mencionadas ejemplificativamente en la ley. Aquí hay una clara violación del principio nullum crimen, sine lege praevia; p. 78.

36 Cfr. Tiedemann, 1985, p. 87.

* La nueva Constitución Política del Perú reitera los mismos principios de la anterior en los artículos 58 y 61 .

${ }^{37}$ Un ejemplo bastante claro es el de los favorecimientos a las empresas extran- 
El sistema de control de precios continuó siendo considerado como el que mejor garantizaba «precios justos» para los consumidores. Sin embargo, el fracaso de esta política saltaba a la vista incluso por el hecho de que los precios de los productos no controlados subían más lentamente que los de aquellos sometidos a control ${ }^{38}$.

Si bien a partir de 1980 el gobierno democrático de turno siguió una política de desmonopolización en cumplimiento de la nueva Constitución, se limitó a los monopolios estatales. Paradójicamente fueron grupos políticos de izquierda los que más reclamaban la dación de una ley antimonopólica que diera verdadero cumplimiento al mandato constitucional. Se afirmaba que la eliminación de monopolios estatales estratégicos como los de la extracción y refinado de petróleo tenía por objetivo favorecer a un grupo de doscientas empresas peruanas y a empresas extranjeras ${ }^{39}$.

En contra de la tendencia general y pese a la existencia del anteproyecto de Ley antimonopólica de 1980, elaborado por el Dr. Roberto Mc Lean, se optó efectivamente por continuar con el sistema de control de precios, promulgando el decreto legislativo 123, erróneamente denominado «Ley de los delitos económicos», ya que éste sólo se refería a los delitos de especulación, acaparamiento y falseamiento de productos de primera necesi$\operatorname{dad}^{40}$.

El sistema de control de precios optado hasta entonces por el legislador peruano había demostrado ser incapaz de cumplir con su finalidad: la protección de los consumidores. Esto no sólo se debía a que en la práctica es casi imposible que se dé el caso de que especialistas incorruptibles pue-

jeras Gloria y Perulac, las que desde su entrada al mercado obtuvieron toda serie de beneficios (liberación de impuestos, aranceles elevados para productos competidores importados, etc.). Detalladamente y con más ejemplos, véase ILD, p. 70 ss.

${ }^{38}$ Comp. ILD, p. 73, donde se menciona que una de las causas principales de esto radicaría en las manipulaciones durante la fijación de los precios controlados.

${ }^{39}$ Manuel Dammert, p. 11 ss.

40 Los tipos en blanco de dicha ley recién fueron completados por los decretos correspondientes tres años más tarde. Antes de estos decretos, los tribunales, no pocas veces, habían declarado improcedentes algunas denuncias por inconstitucionalidad de la ley; Corte Superior de Lima, p. 113 ss. 
dan fijar precios justos, continuamente ajustados a la inflación, sino también porque la propia persecución penal se veía ante enormes problemas de operatividad: las conductas ilícitas estaban demasiado extendidas ${ }^{41}$ para que pudieran ser perseguidas exitosamente con los escasos medios disponibles. Pero además, la misma ley presentaba imprecisiones y vacíos: aparte de los tipos en blanco, se puede mencionar la duplicidad de autoridades sancionatorias (administrativa y penal), la existencia de elementos subjetivos innecesarios en el tipo ( «con la finalidad de...») y el cáracter genérico de la ley que comprendía incluso casos de bagatela, en vez de concentrar la persecución penal a los casos más graves.

Un sistema de control de precios, que tiene en realidad por trasfondo el concepto clásico, pero desacreditado, del «precio justo», es por su naturaleza contrapuesto a una economía de mercado, que se basa en la libre oferta y demanda de bienes y servicios. El sistema de control de precios ha servido para que en nuestro país resulten beneficiados monopolios y oligopolios, contribuyendo así más aún a la crisis económica y al subdesarrollo.

Por estos motivos, conocidos autores latinoamericanos y europeos, así como organizaciones internacionales, recomiendan la introducción de una legislación contra las prácticas restrictivas de la competencia en aquellos países que han optado por una economía de mercado. La recomendación se hace extensiva a los países subdesarrollados, donde además debe considerarse la posibilidad de un tratamiento especial para las empresas trasnacionales ${ }^{42}$.

\subsection{Los delitos contra la competencia en el nuevo Código Penal peruano}

Un importante avance hacia un Derecho de cárteles en el Perú constituyó la

4! Al parecer, el carácter injusto de las conductas sancionadas no podía ser internalizado por los destinatarios de la norma debido a lo «artificial» de un sistema de control de precios. Además el riesgo de sanción penal era mínimo debido a muchos motivos: dificultad de detección, corrupción, prescripción de la acción.

42 Comp. Zaffaroni, p. 13 ss.; Carranza; Biel, p. 290 ss.; Röhnke, p. 92 ss., 313 ss.; OECD, p. 58. 
dación de un nuevo Código Penal en abril de 1991. Entre sus novedades cuenta el título «Delitos contra el orden económico» (artículo 232), donde se tipifican penalmente los abusos de posición «monopólica u oligopólica», así como las prácticas y acuerdos restrictivos en la actividad productiva, mercantil o de servicios, que tengan por objeto «impedir, restringir o distorsionar la libre competencia». Sin embargo, el artículo 232 C.P. remitía a la «ley de la materia», la cual en esa fecha todavía no había sido promulgada. Solamente estaba vigente el decreto supremo n. ${ }^{\circ} 296-90-E F$ que prohibía determinados abusos de posición dominante en el mercado y «comportamientos que limitan la competencia», pero que reservaba el establecimiento de sanciones a otras normas (ejecutivas) reglamentarias. Con esto, obviamente, no se satisfacía el principio de legalidad, ni se podía completar la remisión establecida en el artículo 232 del nuevo Código Penal.

\subsection{La Ley contra las prácticas restrictivas de la competen- cia (LPRC)}

La ley especial recién fue promulgada en noviembre de 1991, bajo el nombre de «Ley contra las prácticas monopólicas, controlistas y restrictivas de la libre competencia» (decreto legislativo 701), en medio de una activa política de desmonopolización (estatal) emprendida por el nuevo gobierno*.

La LPRC significó, sin embargo, al mismo tiempo, un cambio en la orientación sancionatoria del legislador. En efecto, el C.P. solamente preveía sanciones penales en caso de la comisión de prácticas restrictivas en general. La nueva ley redujo las prácticas sancionadas penalmente a determinado número de casos de abuso de poder económico (negativa de venta, discriminaciones e imposición de condiciones comerciales abusivas) y de otras prácticas anticompetitivas.

Pero más grave fue aún el retroceso que significó la técnica jurídica

* Poco antes, en setiembre del mismo año, el artículo 5 del decreto legislativo 668 había reafirmado el principio de prohibición de «todo tipo de exclusividad, limitación y cualquier otra restricción o práctica monopólica en la producción y comercialización de bienes y prestación de servicios de toda clase...», contenido en el artículo 133 de la Constitución de 1979. 
empleada por la LPRC, que incluye en los tipos de abuso de posición dominante el elemento (no previsto en el C.P.) de la verificación del perjuicio o daño al «interés económico general en el territorio nacional». Con esto se retrocedió incluso más allá de la fuente argentina que exige la verificación de un peligro concreto, pues aquí se exige la comprobación de la lesión misma al bien jurídico, que como ya vimos más atrás, es prácticamente imposible. Para evadir este obstáculo, tendría que interpretarse la lesión al «interés económico general» de una manera muy amplia, en el sentido de entender que dicho interés es lesionado cuando se atenta contra la competencia, pues ésta es el instrumento que garantiza el funcionamiento de una economía de mercado, que va en interés de la generalidad.

\section{Los tipos penales de la LPRC}

Cuando la ley se refiere en su artículo 1 a «prácticas monopólicas, controlistas y restrictivas de la competencia», parece indicar que abarcaría más de lo que en la literatura continental se recomienda como punible (las prácticas restrictivas). Esto podría indicar prima facie que la ley adopta el sistema norteamericano de sancionar toda práctica destinada a monopolizar el mercado, y no solamente aquellas que, sin que necesariamente busquen un monopolio, restringen la competencia.

Sin embargo, del estudio sistemático de la ley se deriva que ésta se orienta más bien en el sistema europeo de sanción.

La ley conoce, entonces, dos grandes grupos de prácticas restrictivas (las monopólicas y las controlistas deben ser consideradas también restrictivas): los abusos de posición dominante en el mercado (artículos 3 al 5) y las prácticas concertadas (artículo 6).

\subsection{El abuso de posición dominante en el mercado}

En este ámbito la LPRC peruana ha adoptado la técnica del Derecho de la Comunidad Económica Europea (CEE), ya recepcionado antes por la ley argentina. Esta técnica tiene la ventaja de ser más sencilla y clara que la del sistema alemán, el cual regula separadamente los casos, sin un concepto 
unitario de abuso ${ }^{43}$. No hay que olvidar, sin embargo, lo que ya se dijo sobre la legislación de la Comunidad en el sentido de que la técnica escogida por ésta (tipos abiertos) es comprensible desde el punto de vista de su propia realidad. Por eso, el Derecho penal (y administrativo) de un país no puede recepcionar ciegamente esa técnica, sin correr el riesgo de atentar contra principios fundamentales, como el principio de legalidad y la prohibición de la analogía.

La ley peruana (y la argentina) ha tratado, por eso, de precisar (innecesariamente) los conceptos de «posición dominante» y «abuso» (el Tratado de Roma no lo hace), así como de presentar una lista cerrada de casos en los que se da un abuso de posición dominante sancionado penalmente (artículo 5 , incisos a, b y c).

El Tratado de Roma renunció conscientemente a la precisión de estos conceptos y, por razones de flexibilidad, los dejó en manos de la jurisprudencia. La ley argentina distingue los casos de posición dominante en monopolios y oligopolios (artículo 2), mientras que la ley chilena reformada sólo se refiere a abusos de posición monopólica (artículo 8, lit. c y d).

El artículo 4 de la LPRC incorpora, con otros términos, el criterio desarrollado por la jurisprudencia de la CEE para determinar una posición dominante en el mercado: una empresa tiene posición dominante en el mercado cuando no está expuesta a una competencia efectiva, es decir, cuando puede actuar sin tener en cuenta a los competidores, compradores o proveedores. Para ello, según el Derecho de la CEE, es necesario determinar el producto relevante y el mercado geográfico en el cual debe medirse el poder económico de la empresa. Ambos criterios son recogidos por la ley peruana, según cuyo artículo 4 los factores a tener en cuenta para determinar una posición dominante en el mercado son los siguientes:

1. La participación significativa de las empresas en los mercados respectivos.

${ }^{43}$ Detalladamente, Möschel en Immenga / Mestmäcker, § 22, nota marginal 6 y ss.; Rittner, p. 176. El sistema alemán conoce además dos grandes grupos de abusos de posición dominante en el mercado: 1 . Monopolios y cuasimonopolios ( $\$ 21$, párrafo primero) y 2. Oligopolios ( $\$ 22$, párrafo segundo); véase Rittner, p. 334 ss. 
2. Las características de la oferta y la demanda de los bienes y servicios.

3. El desarrollo tecnológico o servicios involucrados.

4. El acceso de competidores a fuentes de financiamiento y suministro, así como a redes de distribución.

La redacción de la ley («... factores tales como:») da a entender que éstos no serían los únicos factores a considerar para determinar la posición dominante en el mercado, con lo cual se deja cierto ámbito de actuación a la jurisprudencia para que desarrolle otros criterios que lleven a una determinación más precisa de tal concepto.

La ley peruana supera así a la ley argentina, en cuanto ésta sólo admite criterios del mercado geográfico (monopolios y oligopolios) para determinar la posición dominante. La consideración del «producto relevante» es vital, pues, como lo demuestran la jurisprudencia europea y la norteamericana, una empresa que tiene el monopolio de un producto determinado no puede atentar contra la competencia si este producto es fácilmente reemplazable por otro.

Pero, por otro lado, la ley peruana utiliza en el artículo 5 un concepto bastante dudoso de abuso: que la empresa en posición dominante actúe de manera indebida «con el fin de obtener beneficios y causar perjuicios a otros, que no hubieran sido posibles de no existir posición de dominio». La prueba de tal elemento subjetivo de la finalidad debe resultar complicadísima porque otorga la posibilidad de alegar cursos causales alternativos que liberarían de responsabilidad al autor: el caso de que los beneficios obtenidos y perjuicios causados a otros también hubieran sido posibles de no existir la posición de dominio. Claro está que a esta dificultad se le agrega aquella propia de los elementos subjetivos: de poder probar que la acción se emprendió precisamente con la finalidad reprobable de obtener beneficios y causar perjuicios.

Más objetivo es el criterio de la jurisprudencia comunitaria que entiende como abuso todo «aprovechamiento excesivo de las ventajas competitivas», es decir, que éste se da cuando «se expone a competidores y consumidores a situaciones compulsivas que no se basan en la interrelación de oferta y demanda, sino que son ocasionadas por acciones y omisiones de 
empresas dominantes en el mercado» ${ }^{44}$. En todo caso, parece preferible renunciar al criterio de «abuso», como lo hace la ley argentina, en la medida en que los tipos contenidos por la misma ley ya representan casos de abuso per se, que se derivan de una posición dominante en el mercado. El hecho de que el Derecho de cárteles comunitario no pueda prescindir de un concepto de «abuso» es explicable dada la técnica empleada de tipos abiertos, pues sólo así puede garantizarse un criterio orientador para la aceptación de nuevos casos mediante la vía jurisprudencial. Ése no es precisamente el caso de nuestras legislaciones, donde ya la misma ley tiene que fijar definitivamente los casos de abuso. Ésta también parece ser la tendencia de la jurisprudencia chilena, la cual hace constatación, primero, de una posición monopólica, y, después, del abuso, en función de la conducta cometida. Así, la Comisión Resolutiva consideró la existencia de «abuso de posición monopólica» de la Empresa de Electricidad Chilectra, porque ésta impuso al usuario, sin ninguna explicación, el pago injustificado de una cantidad por consumo. Según la ley peruana aquí no sería comprobable el «abuso», pues difícilmente podría afirmarse que la empresa quería perjudicar al usuario y que esto no se hubiera producido de no existir una posición dominante en el mercado.

A nivel de los tipos penales, la ley peruana conoce solamente tres casos de abuso de posición dominante:

\subsubsection{La negativa de venta (artículo 5, lit. a)}

La configuración típica proviene del Derecho comunitario ${ }^{45}$, también presente en la ley argentina (artículo 41 , lit. g), aunque no como un caso de abuso de posición dominante, sino como práctica concertada.

44 Comp. Dannecker / Fischer-Fritsch, p. 20 ss.

45 En el caso Zoja, p.e., además de otras prácticas restrictivas se comprobó una negativa de venta: la empresa trasnacional Commercial Solvents Corporation (CSC) trató de absorber a la empresa farmacéutica italiana Zoja, ordenándole a su filial italiana ICI que se negara a vender a aquélla la materia básica necesaria para producir un medicamento, e impidiendo que otras empresas productoras de la misma materia básica pudieran abastecer a Zoja. Vid. Tiedemann, 1985, p. 85. 
Sin embargo, el texto legal peruano es más limitado que el argentino y que el europeo, pues sólo se refiere a «satisfacer demandas de compras de productos», es decir, a negativas de venta de productos, mientras que las otras legislaciones se refieren también a negativas de compra y a servicios.

La jurisprudencia chilena ha conocido también estos casos. P. e., en el caso Sedylán, un mayorista de textiles se negó a vender productos a un minorista porque éste no quiso aumentar los precios de venta a los consumidores $^{46}$. Pero cuando la práctica, en el caso concreto, no atenta efectivamente contra la libre competencia, la Comisión no admite casos de negativa de venta aunque los actores hayan tenido una posición dominante. Tal sería el caso, p. e., de una cervecería que se niega a vender a comerciantes mayoristas, para dedicarse ella misma a la venta del producto directamente a los minoristas ${ }^{47}$, o cuando un producto solamente es ofrecido a las empresas nacionales por la filial, situada en el extranjero, de una empresa matriz que también produce el mismo producto en el país y que los exporta a precios mucho menores que los de sus filiales ${ }^{48}$.

\subsubsection{Discriminación (artículo 5, lit. b)}

El tipo penal peruano de las discriminaciones corresponde casi literalmente al del artículo 86, párrafo 4, lit. c. del Tratado de la CEE: «La aplicación (en el tráfico de los negocios) de condiciones desiguales para prestaciones equivalentes que coloquen a unos competidores en una situación desventajosa frente a otros.» Pero, además, el texto peruano contiene, acertadamente, los criterios que llevan a la exclusión de la tipicidad de discriminaciones (los que tuvieron que ser desarrollados por la jurispruedencia comunitaria): el otorgamiento de descuentos y bonificaciones que correspondan a las prácticas comerciales generalmente aceptadas. Estas excepciones ya habían sido desarrolladas por la jurisprudencia comunitaria. En realidad, con esto no se hace más que considerarse que tales conductas son inmanentes a una libre

46 La Comisión Resolutiva impuso una multa, y solamente no formuló denuncia penal atendiendo a que el autor no tenía antecedentes; sentencia n. ${ }^{\circ} 25$ de 1976 , en Malamud Goti, p. 74 ss.

47 Caso de las Cervecerías Unidas, RDJy GT, 1988-II, p. 166 ss.

48 Caso del mercado del yodo, RDJyGT, 1987-II, p. 25 ss. 
competencia en el marco de la libertad contractual y de la libertad de contratación, y que solamente tendrían que ser prohibidas y tipificadas aquellas conductas que son indeseables y graves desde el punto de vista de la competencia ${ }^{49}$.

Aquí la ley argentina también presenta un vacío, pues, como ya se vio antes, las discriminaciones del artículo 41 , lit. f sólo se sancionan penalmente si provienen de acciones concertadas, mas no de abusos de posición dominante.

Por su parte la Comisión Resolutiva chilena ha desarrollado jurisprudencia referida a casos, no solamente de las tradicionales discriminaciones mediante representantes comerciales exclusivos ${ }^{50}$, sino también ha impuesto sanciones por conductas similares como «entorpecimientos» ${ }^{51}$, «bloqueo de entrada al mercado» ${ }^{52} y$ «dumping $»^{53}$.

49 Tiedemann, 1976-A, p. 136 ss.

so Entre otros casos destacan, por su magnitud, las ventas discriminatorias de autos y repuestos efectuadas por Citröen Chile S.A.C. en favor de sus distribuidores exclusivos; véase RDJyGT, 1986-II, p. 26 ss. Véase también el caso de los productores de alambres; ibidem, 1986-II, p. 7 ss. La Comisión Resolutiva siempre enfatiza que los precios especiales sólo pueden resultar de circunstancias objetivas (tipo de pago, cantidad comprada, etc.) y no de circunstancias subjetivas (quién es el comprador).

51 Así el caso de las fotocopiadoras, RDJyGT, 1986-II, p. 42 ss. y el de las trasmisiones de partidos de fútbol, ibidem, 1982, p. 612 ss. En este último, la Asociación Nacional de Fútbol de Chile trató de impedir, valiéndose de sus numerosas influencias, que un canal privado de televisión emitiera «en vivo» partidos de fútbol de equipos extranjeros a la misma hora que los partidos de equipos nacionales.

52 La empresa estatal ENAP elevó, en 1987, la cantidad mínima de petróleo que ponía a la venta, y modificó las condiciones de venta, de tal manera que se ofrecían descuentos de hasta el $3 \%$ para aquellas compras realizadas contractualmente. Esto desfavorecía a otros competidores (más débiles) que querían entrar al mercado.

53 La Comisión Resolutiva no acepta fácilmente casos de dumping. Sólo lo hace si la venta por debajo del costo se realizó durante un tiempo apreciable y si no resultó a manera de defensa contra conductas similares de otros competidores (guerra de precios); véase el caso Comar-Dicomac, RDJyGT, 1989-II, p. 72 ss., y el caso Savory S.A.I.C., ibidem, 1989-II, p. 129 ss. 


\subsubsection{Imposiciones contractuales abusivas (artículo 5, lit. c)}

También aquí el tipo peruano presenta una notoria similitud con los tipos del Derecho comunitario (artículo 86, lit. d) y de la ley argentina (artículo 41 , lit. d).

En la jurisprudencia comunitaria se presentan casos de imposiciones contractuales de exclusividad o descuentos contractuales de «fidelidad» ${ }^{54}$.

En la ley argentina, éste es el único caso de abuso de posición dominante sancionado penalmente, aunque en la práctica jurisprudencial se conocen muy pocos. En el caso Y.P.F., la empresa frigorífica denunciada imponía a sus clientes la compra de hielo producido por determinada empresa. Aquí la autoridad argentina, inexplicablemente, sólo constató la configuración de un ilícito administrativo, según el artículo 1 de la ley ${ }^{55}$.

Adicionalmente, la ley argentina presenta la dificultad, por lo menos teórica, de que exige que las condiciones contractuales impuestas, «por su naturaleza y con arreglo a los usos comerciales» ( $;$ ambas deben darse acumulativamente!) «no guarden relación con el objeto de tales contratos», cuando debiera bastar la existencia de cualquiera de los dos supuestos, como en la ley peruana.

La jurisprudencia chilena también conoce estos casos. Así, la Comisión Resolutiva sancionó con elevadas multas a la empresa extranjera Automotriz Corfo Citröen y formuló la respectiva denuncia penal, porque ésta reiteradamente imponía condiciones abusivas a sus clientes, tales como la compra de repuestos a determinada empresa, la venta de los productos dentro de determinadas áreas fijadas por ella, y el mantenimiento de los precios que ella fijaba ${ }^{56}$. Por otro lado, no se consideró imposición abusiva de condiciones contractuales, que las distribuidoras de combustibles (ESSO Chile, Shell Chile, Copec y otras) obligaran a las estaciones de servicios compra-

54 Véase el caso Hoffmann-La Roche o el caso IBM, analizados por Tiedemann, 1980, p. 20 ss. También Emmerich, p. 584 ss.

s5 Otamendi, p. 765.

56 Véase Malamud Goti, p. 69 ss. 
doras, que usaban el distintivo de la empresa, a que no vendieran productos de otras empresas ${ }^{57}$.

En el ámbito de los abusos de posición dominante se puede comprobar, finalmente, que, aparte de las deficiencias técnicas, la ley, en general, presenta importantes vacíos legales. Efectivamente, no se comprende casos de dumping, entorpecimientos (a la actividad de competidores), empleo de amenazas y de represalias económicas, etc., cuya sanción penal, además, tendría que considerarse frente a una mera sanción administrativa ${ }^{58}$. Otras figuras mencionadas en los anteproyectos peruanos ${ }^{59}$ y en la ley argentina (artículo 41, lit. i, j), como la disminución dolosa de la producción, el abandono de bienes perecibles, la destrucción de bienes y productos para ocasionar su limitación, etc., no fueron contempladas por el legislador peruano, quien al parecer consideró que tales conductas, o ya se encuentran comprendidas por otras figuras o no son dignas de sanción penal ni administrativa. En todo caso, estas conductas tendrían que ser estudiadas más a fondo para una correcta valoración jurídica.

\subsection{Acciones concertadas y otras prácticas restrictivas}

La ley peruana denomina al segundo grupo de ilícitos contra la competencia como «prácticas restrictivas de la competencia». Sin embargo, este término tiene una acepción más genérica, pues también los abusos de posición dominante en el mercado son prácticas restrictivas de la competencia. Por eso preferimos hablar aquí de «acciones concertadas». Bajo este concepto debe entenderse, entonces, principalmente todos los acuerdos de cárteles horizontales y, por lo demás, todas aquellas prácticas restrictivas prohibidas que no provienen de un abuso de posición dominante.

La LPRC sanciona todos aquellos «acuerdos, decisiones, recomendaciones, actuaciones paralelas o prácticas concertadas entre empresas que produzcan o puedan producir el efecto de restringir, impedir o falsear la

57 RDJyGT, 1990-II, p. 37 ss.

58 Sobre la necesidad y el merecimiento de pena de cada una de estas figuras, ampliamente, véase Tiedemann, 1976-A, p. 120 ss.

59 Véanse los comentarios en ILD, p. 92 ss. 
competencia» (artículo 6, párrafo primero). Esta definición, con algunas adecuaciones, proviene del artículo 85 del TCEE. Comparativamente destaca, primeramente, en el texto de la ley peruana, la introducción de dos modalidades de comisión de las prácticas restrictivas no previstas en el texto comunitario: las recomendaciones y las conductas paralelas ${ }^{60}$. En segundo lugar, la ley exige que las conductas produzcan «o puedan producir» el efecto lesivo a la competencia y, en concordancia con el artículo 3, que se generen así perjuicios para el interés económico general. Es decir, para la ley, aquí, a diferencia de los abusos de posición dominante, basta que las conductas generen el peligro de que se produzca una lesión al bien jurídico (por medio de un peligro a la competencia). La jurisprudencia comunitaria tiende precisamente a exigir tal peligro para afirmar la existencia de la conducta ilícita, si bien el texto de la ley habría podido ser interpretado más rigurosamente: según el artículo 85 TCEE la conducta debe ser idónea para perjudicar el comercio entre los Estados miembros y debe existir la finalidad dirigida contra el bien jurídico o el efecto dañoso ${ }^{61}$.

Aquí también se puede apreciar una confusión proveniente de la recepción del Derecho comunitario en la ley peruana. Es lógico que la normativa comunitaria se viera obligada a implantar, mediante el párrafo primero del artículo 85, algunos criterios para que la jurisprudencia pudiera, en el futuro, desarrollar nuevos supuestos de prácticas restrictivas. Dado que la ley peruana no puede utilizar tal sistema, sólo tenía que haber tipificado, con la mayor precisión, los casos de acuerdos, prácticas concertadas, etc., y no haber intentado dar un concepto de ellas en el párrafo primero del artículo 6. Esta contradicción sistemática resulta bastante notoria en el caso de las «recomendaciones»: el párrafo primero se refiere a ellas, pero los tipos que siguen a continuación describen acciones específicas, entre las cuales no

60 La restricción de la competencia también puede provenir de «recomendaciones» que se hagan unas empresas con otras, a fin de adoptar determinada conducta en el mercado. Por eso la GWB alemana se refiere expresamente a estas conductas en el artículo 38 , inciso primero, números 10 y 11 , inciso 2 , número 1 .

También las «conductas paralelas» tienen que ser expresamente previstas en la ley, pues no siempre las empresas celebran acuerdos anticompetitivos, sino «pactos entre caballeros», sin obligación contractual alguna, pero que se cumplen. Especialmente ilustrativo es el famoso caso de los colorantes; vid. Tiedemann, 1992, p. 63 ss.

61 Dannecker / Fischer-Fritsch, p. 14. 
cuentan las recomendaciones. Cierto es que puede entenderse, sistemáticamente, que el párrafo primero amplía las acciones típicas de los casos planteados en el artículo 6. Pero, por un lado, ello no sería posible en aquellos casos en que la ley se refiere expresamente a «concertaciones» (incisos a y d), y por otro lado, se atentaría contra la seguridad jurídica al no establecerse tipos claros.

El sistema alemán es más complicado. La GWB declara primeramente sin efecto todos los acuerdos, decisiones, etc., realizados bajo un fin común (artículo 1). Solamente si los actores hacen caso omiso de esta declaración legal, la ley prevé una sanción contravencional (artículo 38). Pero, aparte de que parece poco practicable esperar hasta la ejecución de los acuerdos ilícitos para poder actuar contra ellos, la prueba del conocimiento de su invalidez (error de prohibición), así como la de la finalidad común de los actores, lleva a considerables problemas. Lo mismo sucede con otros conceptos como la «idoneidad para influenciar en el mercado» y el «mercado relevante».

La ley argentina se refiere, en casi todos los tipos penales del artículo 41 , a acciones concertadas, las cuales, en concordancia con el artículo 1, deben representar un peligro concreto para el bien jurídico del interés económico general. No se dan mayores definiciones, como en el caso peruano, que no harían más que dificultar la aplicación de la ley.

En el caso del sistema chileno, como ya se observó anteriormente, dada la amplitud de los tipos de cártel la jurisprudencia está facultada para configurar las formas de restricciones a la competencia.

\subsubsection{Acuerdos sobre precios y otras condiciones de comerciali- zación (artículo 6, lit. a)}

Una vez más destaca aquí la influencia de la legislación comunitaria en la legislación peruana. Sin embargo, a diferencia del artículo 85, lit. a TCEE, el texto peruano presenta la novedad de que la «concertación» debe ser «injustificada», proveniente, al parecer, de la literatura argentina, la cual a su vez tiene su origen en la jurisprudencia norteamericana. Si esto es así, la ley no se estaría refiriendo aquí, de manera reiterativa, a que la conducta tí- 
pica, para ser punible, no debe ser excluida debido a la existencia de una causa de justificación. Se trataría, más bien, de un elemento típico especial que excluiría de la esfera de la tipicidad a aquellos acuerdos «justificados», en el sentido de que éstos sean razonables según las prácticas comerciales ${ }^{62}$. Esto, sin embargo, es bastante discutible, pues constituye un tipo abierto cuya concretización se estaría dejando en manos de la jurisprudencia o, en última instancia, de los peritos.

En contra de lo que dice el primer párrafo del artículo 6 (descripción genérica de las conductas sancionadas), la configuración específica del tipo en cuestión no permite incluir las «simples recomendaciones» (el hecho de que una empresa recomiende a otra determinada conducta anticompetitiva), ya que una «concertación» presupone siempre un entendimiento entre por lo menos dos partes. Sólo aquellas recomendaciones que han tenido éxito (la otra parte realiza la conducta recomendada) podrían eventualmente interpretarse como «concertación». Este camino no deja de ser dudoso, sobre todo en el campo del Derecho penal, donde la prohibición de la analogía y el principio de certeza impiden interpretaciones demasiado amplias.

La jurisprudencia tiene la tarea de esclarecer otras cuestiones, como p.e., la posibilidad de comprender, a través de la prohibición de la «concertación injustificada de (...) otras condiciones de comercialización», casos en los cuales se puede influenciar indirectamente en los precios. La jurisprudencia de la CEE y la ley argentina pueden servir aquí de ejemplo. Pero no debe olvidarse, en este contexto, que tanto los tipos argentinos como los peruanos, al contrario de las normas de la CEE y de la ley chilena, no permiten mucho espacio para su ampliación mediante la interpretación.

62 Según Cabanellas, existe la posibilidad, p.e., de que la competencia sea reforzada precisamente mediante acuerdos sobre condiciones de negociación como la implantación de un sistema común de distribución; p. 326 ss. La jurisprudencia argentina «justificó» la realización de alzas paralelas (no se pudo probar la existencia de acuerdos, sino simplemente de actuaciones paralelas) de los precios del pan y de la leche en los años 1967 y 1968, respectivamente, porque las empresas se habrían visto amenazadas en su existencia de no haberlo hecho. Es dudoso, sin embargo, que la «justificación» aquí esté referida a la tipicidad. Vid. Hendler, 1982-B, p. 1014 ss. 
La jurisprudencia chilena muestra variados casos de fijaciones de precios y conductas similares. Muchas veces no se puede probar que haya habido un «acuerdo» entre las partes, pero la Comisión Resolutiva deduce su existencia, sobre todo cuando queda clara la imposibilidad de que los costos individuales hayan sido idénticos ${ }^{63}$. En algunos casos el alza uniforme se puede deber a otros factores, distintos de un concierto. Así, no se impuso ninguna sanción a los corredores de bolsa chilenos que uniformemente elevaron en $0,1 \%$ el monto de sus comisiones, porque no se pudo probar la existencia de un acuerdo; la uniformidad en el incremento se habría debido, más bien, a los buenos servicios de información de la bolsa ${ }^{64}$.

\subsubsection{Reparto (o distribución) de mercados y de otras fuentes de abastecimiento (artículo 6, lit. b)}

Ésta constituye una de las prácticas restrictivas más antiguas. La ley peruana introduce un tipo idéntico al del TCEE, artículo 85, lit. c. Precisamente aquí la jurisprudencia comunitaria se ha mostrado bastante activa llegando a imponer multas elevadísimas. Por otro lado, se ha comprobado que los repartos de mercado van frecuentemente acompañados de otras prácticas restrictivas $^{65}$.

La ley argentina también conoce esta práctica. El texto de la nueva ley significó incluso un avance con respecto al de la ley anterior, pues es más amplio y prescinde de elementos subjetivos que dificulten la prueba (artículo 41 , lit. e) ${ }^{66}$.

${ }^{63}$ Así en el caso de las alzas uniformes de los precios del pan y de la leche; vid. Malamud Goti, p. 113 ss. También el caso de las alzas de precio del pan y de la gasolina en los años 1982 y 1984, respectivamente; vid. RDJyGY, 1985-II, p. 80 ss. 1986-II, p. 74 ss.

${ }^{64}$ RDJyGT, 1989-II, p. 94 ss.

65 Vid. el caso de la quinina o el caso Pioneer, comentados por Tiedemann en Tiedemann 1992, p. 64 ss.

${ }^{* 6}$ Comp. Malamud Goti, p. 122 ss.; una exposición detallada sobre el tema ofrece Cabanellas, p. 431 ss. 
También en la jurisprudencia chilena se han presentado, con cierta frecuencia, casos de reparto de mercados. Así, la Comisión Resolutiva impidió un reparto de mercados entre las empresas de telecomunicaciones más importantes del país, ENTEL S.A. y C.T.C. S.A., maniobra que estaba dirigida por el principal accionista de ambas, la empresa CORFO. Ésta alegaba que la medida perseguía más bien una racionalización de los recursos y, por lo demás, la ley podía fijar en cualquier momento las tarifas para evitar alzas abusivas. Sin embargo, la Comisión consideró que tales acuerdos eliminaban la competencia ante ambas empresas y conducían a un monopolio ${ }^{67}$. A pesar de todo, la autoridad chilena permite repartos de mercado si ellos mejoran la distribución y van en beneficio de la generalidad ${ }^{68}$.

\subsubsection{Reparto de cuotas de producción (artículo 6, lit. c)}

Esta práctica anticompetitiva está estrechamente ligada a los repartos de mercado. El texto peruano aparece bastante simple e insuficiente en comparación con los del artículo 41 , lit. b de la ley argentina y artículo 85 , lit. b del TCEE. Para estos últimos, las acciones concertadas no solamente están referidas a la producción, sino también a los demás aspectos de la actividad económica (venta, desarrollo técnico, inversiones), y, por lo demás, la mejor configuración de sus tipos permite que se comprendan mayores conductas anticompetitivas. Efectivamente, el reparto de cuotas de producción, según el texto peruano, constituye solamente una de las acciones posibles comprendidas en los textos argentino y europeo, pues ellos se refieren ampliamente a «limitar [fijar cuotas] o controlan, mediante acciones concertadas, la producción, la venta, el desarrollo técnico o las inversiones.

Por el contrario, no se conocen ejemplos que provengan de la jurisprudencia argentina, donde, al parecer, los tribunales prefieren aplicar tipos más genéricos, que no requieren una prueba tan específica de las acciones (p.e., el tipo administrativo del artículo 1). Así, en 1970, cuando las empresas frigoríficas Swift, Fasa y Anglo fueron acusadas de concertar omisiones de compra de novillos (limitación concertada de compra), la justicia argenti-

67 RDJyGT, 1987-II, p. 125 ss.

68 Vid. el caso de las salinas en Malamud Goti, p. 122. 
na solamente aplicó el tipo genérico de «acciones que impiden o tienden a impedir la competencia», vigente en ese entonces, pese a tener a su disposición un tipo más específico similar al correspondiente de la ley actualmente vigente ${ }^{69}$.

Por su parte, la ley chilena contiene en su artículo 2, lit. a, un «ejemplo-tipo» referido a los repartos de cuotas de producción, disminución o paralización de la producción, el cual, unido al amplio margen de actuación que la ley concede a las autoridades chilenas, no debe generar ningún problema de aplicación.

\subsubsection{Concertación en la calidad de los productos (artículo 6, lit. d)}

La acción típica contemplada aquí por la ley peruana, está incluida en los tipos de «limitación o control de la producción», ya mencionados, de las legislaciones argentina y comunitaria. Pero mientras para las legislaciones extranjeras la acción típica tenía que deducirse por la vía interpretativa, y, consecuentemente, su efectiva sanción podía restringirse según los últimos alcances de la ciencia jurídica y económica, la inclusión en la ley peruana de un tipo específico obliga a su aplicación por el juez. Esto no es nada alentador; la dañosidad de tales prácticas no siempre es fácil de probar, pues no pocas veces se emplean, más bien, como medida de racionalización que puede beneficiar tanto a la competencia como a los consumidores ${ }^{70}$.

En todo caso, en la práctica, los acuerdos no solamente suelen referirse a la calidad del producto, sino también a otros factores, como el precio o la productividad, con lo cual su merecimiento de pena aparecería más níti-

69 Vid. Hendler, 1982-B, p. 1014 ss.

70 Vid. Cabanellas, p. 363 ss. ILD propone que la punibilidad de la fijación de la calidad de productos se limite a aquellos acuerdos entre productores o entre comerciantes, pues ellos, de esta manera, buscarían no competir. Así, se excluirían aquellas conductas en las compras y ventas de insumos en que las empresas dejan de comprar a proveedores ineficientes para mejorar la calidad de su producto (ILD, p. 93). 
do. Según lo expuesto, un caso «puro» de acuerdo (punible) sobre la calidad de un producto rara vez podría llegar a ocupar a la justicia (penal) peruana.

\subsubsection{Discriminaciones e imposiciones contractuales mediante ac- ciones concertadas (artículo 6, lits. e y f)}

La fuente de la doble regulación de estas figuras (como abuso de posición dominante y como práctica concertada) es la legislación comunitaria (artículo 85, lits. d y e). La jurisprudencia muestra, sin embargo, que los casos de discriminación y de imposiciones contractuales son rara vez subsumidos como tipos de acciones concertadas, pues en este ámbito otros tipos pueden superponerse a ellas (p.e., fijaciones de precios) ${ }^{71}$.

En Alemania, los «contratos o cláusulas atados» sólo son sancionados de manera mediata (parágrafo 38 , párrafo $1, \mathrm{n} .{ }^{\circ} 1$, concordado con el parágrafo 18 , párrafo $1, n .^{\circ} 4$, de la GWB): primero tiene que existir una disposición inapelable de la autoridad administrativa que declare nulo el contrato correspondiente, antes de poder aplicar una sanción. Pese a ello, en la práctica las autoridades tienden más bien a afirmar en tales casos la presencia de un abuso, según el parágrafo 22, párrafo 4 y el parágrafo 26 , párrafo $2^{72}$. Por el contrario, las discriminaciones se contemplan claramente como aprovechamiento abusivo de una posición dominante, si bien la práctica hace poco uso del tipo de abuso del parágrafo 38 , párrafo $1, n{ }^{\circ} 8$, concordado con el parágrafo 26 , párrafo $2^{73}$.

La ley argentina presenta aquí una notoria diferencia en la regulación penal de ambos casos. Mientras que, para la afirmación de una discriminación, ésta tiene que haber sido producto de una acción concertada (artículo 41 , lit. h), la prohibición de subordinación a condiciones contractuales (abusivas) (artículo 41, lit. d) presupone, según la interpretación doctrinaria, una posición de dominio en el mercado.

71 Cabanellas, p. 543 ss.

72 Comp. Emmerich, en Immenga / Mestmäcker, comentario al $\S 18$, nota marginal n..$^{\circ} 138$ ss.

73 Tiedemann, en Immenga / Mestmäcker, comentario previo al $\S 38$, nota marginal n. ${ }^{\circ} 11$. 
La jurisprudencia chilena no conoce una doble configuración de los tipos de discriminación y de imposición de condiciones contractuales como la de la ley peruana. Ella se ocupa en la práctica casi exclusivamente de casos provenientes de posiciones dominantes en el mercado, en los cuales debe haberse producido un daño a la competencia y verificarse una ausencia de «razonabilidad» en la aplicación de práctica ${ }^{74}$.

\section{Observaciones finales}

La nueva ley peruana de defensa de la competencia ha significado un importe paso para el establecimiento de una verdadera economía de mercado en el Perú.

Sin embargo, se aprecian ciertas deficiencias en la técnica jurídica empleada que podrían dificultar la efectiva aplicación de sus tipos. Por otro lado, quedan todavía algunos importantes vacíos legales que dejan impunes conductas cuya dañosidad social es bastante apreciable, tal como ya se ha visto en su momento.

Para finalizar, queremos aquí destacar brevemente otro aspecto que no puede soslayarse, referido a la idoneidad del sistema (europeo) empleado en la protección de una economía de mercado de un país subdesarrollado.

En principio, la idea de agrupar las prácticas restrictivas de la competencia en abusos de posición dominante en el mercado, por un lado, y prácticas concertadas, por el otro, se ajusta a las tendencias más modernas del

74 Así, p.e., la Comisión Resolutiva consideró que cuando los vendedores mayoristas de cintas de video hacían depender la venta de películas famosas a la compra de otras de mucha menor calidad, no se daba la figura de imposición abusiva de condiciones contractuales, pues, en el caso dado, no se lesionaba la competencia ya que la venta acoplada regía solamente durante treinta días y constituía la única manera de negociar los videos de mala calidad, los cuales a su vez les habían sido impuestos contractualmente a los mayoristas por empresas norteamericanas. Sin embargo, se afirmó en el mismo caso la existencia de «barreras a la entrada al mercado" por parte de los mayoristas, ya que éstos exigían a los nuevos clientes que compraran una cantidad mínima de 100 cintas de video; RDJyGT, 1990-II, p. 140. 
Derecho de cárteles (europeo). Sin embargo, esto significa que ya no se sanciona (como en el sistema norteamericano) la monopolización, sino solamente a aquella empresa que tiene posición dominante en el mercado (sea en forma de monopolio u oligopolio), que hace uso abusivo de su poder económico. No interesa que se haya alcanzado una situación de monopolio ni que esta situación se mantenga, siempre y cuando de ésta no se deriven abusos tipificados en la ley (y que puedan ser probados durante el proceso). La nueva ley peruana, entonces, deja intactas las estructuras monopólicas (privadas) existentes en el mercado, a las que solamente se prohibe que cometan abusos de poder. Ni siquiera se establece un órgano de vigilancia de fusiones, como en el Derecho comunitario, con facultad de controlar y, de ser necesario, disolver los monopolios.

Esta carencia resulta particularmente grave cuando se trata de un mercado débil, expuesto a la actuación impune de poderosas empresas trasnacionales, las cuales no han demostrado, en el pasado, haber precisamente omitido cometer prácticas abusivas ${ }^{75}$. La ventaja de poder trasladar costos y ganancias dentro de la economía mundial, casi de manera arbitraria, les posibilita el empleo de discriminaciones en precios y descuentos, así como contratos de exclusividad, como parte de su estrategia económica, ya que el riesgo de que se pruebe la conducta abusiva es mínimo ${ }^{76}$. Es por eso que, mientras no existan acuerdos de cooperación al respecto entre los países afectados, se recomienda el empleo de determinadas medidas procesales aplicables a las empresas trasnacionales; p.e., considerar que la empresa matriz y sus filiales conforman una unidad económica, pese a que jurídicamente representan distintas personas («disregard of legal entity»). Consecuencia práctica de esta concepción sería dar carácter de indicio, durante un proceso, a la negativa de la sociedad matriz de dar informaciones sobre una filial ${ }^{77}$.

Tal vez hubiera sido preferible, por ello, haber introducido una prohibición general de monopolización, contemplando la posibilidad de autorizar

75 Tiedemann, 1980, p. 14 ss, 21 ss.; y 1978-A, p. 275 ss.; Rohnke, p. 67 ss.

76 Cfr. Tiedemann, 1989 , p. 927 ss. Véase también el informe detallado al respecto de las Naciones Unidas, NATIONS UNIES, citado en nuestra bibliografía.

77 Vid. dos de los más famosos casos provenientes de la jurisprudencia comunitaria: el caso de los colorantes y el de Continental-Can, en Mireille Delmas-Marty, p. 76; Dannecker, 1991, p. 287 ss. 
fusiones, si éstas a pesar de constituir un monopolio no atentan contra la libre competencia, o de disolverlas en caso contrario. Tal concepción, similar a la que en la práctica aplica la Comisión Resolutiva chilena, habría evitado los problemas arriba expuestos, y, en todo caso, habría resultado más idónea en consideración a la enorme desventaja en la que se encuentran las empresas nacionales con respecto a las trasnacionales.

Las modificaciones más urgentes a la ley peruana tienen, por lo tanto, que llenar los vacíos de protección al bien jurídico y suplir las deficiencias que supone la recepción del sistema europeo. Se recomienda, en consecuencia, las siguientes medidas:

a) En el marco de los abusos de posición dominante: incluir nuevos tipos penales (sin descuidar el principio de legalidad) tales como amenazas y represalias económicas, dumping y entorpecimientos. Debe, además, eliminarse el concepto de «abuso» en la ley, pues los tipos específicos ya presuponen la comisión de un abuso.

b) Debe introducirse un control previo de las fusiones de empresas, contemplando además la posibilidad de disolver las fusiones existentes o autorizadas.

c) En el marco de las prácticas concertadas, tendrían que introducirse correspondientes tipos penales (sobre boicott) y administrativos (para las recomendaciones anticompetitivas entre empresas).

d) Debe estudiarse cuidadosamente la posibilidad de introducir algún organo de control de las empresas trasnacionales. Paralelamente queda en manos de la jurisprudencia desarrollar criterios procesales más practicables, como el de la unidad económica.

e) Preventivamente, podría otorgarse facultad a las autoridades peruanas para que absuelvan consultas con carácter vinculante relativo (excluyendo solamente la sanción), tal como en Chile.

f) Aunque la jurisprudencia podría llegar a una interpretación más o menos satisfactoria, sería preferible que se modifique el presupuesto legal de daño al «interés económico general», en el sentido de un peligro (abstracto) al bien jurídico de la «libre competencia» misma. 


\section{Bibliografia}

BAUMANN, Jürgen

1985 «Zum Ärgernis Submissionsbetrug», en Festschrift für Dietrich Oehler, Colonia, p. 291 ss.

BIEL, Jörn

1979 Multinationale Unternehmen, München.

CABANELLAS, Guillermo

1983 Derecho antimonopóico y de defensa de la competencia, Buenos Aires.

CÁRDENAS, Emilio

1984-A «Características de un abuso de posición dominante», en La Ley, Buenos Aires.

CARRANZA, Elías

1982 «Desarrollo y tendencias de la criminalidad y algunos criterios para su prevención», en ILANUD, San José de Costa Rica.

CORTE SUPERIOR DE LIMA

1988 Jurisprudencia Penal, Lima.

DAMMERT, Manuel

1985 «Proyecto de ley sobre tipificación de delitos de monopolio, entreguismo, terrorismo y genocidio, señalados en la Constitución política de 1979», en La izquierda en el parlamento, Lima, p. 11 ss. 
DANNECKER / FISCHER-FRITSCH

1989 Das EG-Kartellrecht in der Bußgeldpraxis, Colonia.

DANNECKER, Gerhard

1989 «Gesetzgeberische Massnahmen zur Bekämpfung der Wirtschaftskriminalität in der BRD», en Diritto Penale dell'economia, CEDAM, p. 672 ss.

1991 «Die Verhängung von Geldußen gegen Unternehmen als Mittel zur Durchsetzung des Europäischen Wettbewerbsrechts», en Monatschrift für Kriminologie, p. 268 ss.

DELMAS-MARTY, Mireille

1980 «Strafbarkeit und Strafhaftung multinationaler Unternehmen», en Multinationale Unternehmen und Strafrecht, Klaus Tiedemann (editor), p. 69 ss., Colonia.

EMMERICH, Volker

1991 Kartellrecht, Munich.

FARGOSI / STIGLITZ

1990-D «La ley de defensa de la competencia y la responsabilidad civil», en La Ley, Buenos Aires, p. 918 ss.

GEERDS, Detlev

1990 Wirtschaftsstrafrecht und Vermögensschutz, Lübeck.

GUTIÉRREZ, Pedro

1987-II «Aproximación al estudio de la legislación sobre monopolios y la defensa de la competencia», en Jurisprudencia Argentina, Buenos Aires, p. 833 ss.

HENDLER, Edmundo

1981 «Comentarios a la ley de defensa de la competencia», en Doctrina Penal, Buenos Aires, p. 311 ss.

1982-B «Los delitos de la ley de defensa de la competencia», en La Ley, Buenos Aires, p. 1011 ss. 
IMMENGA / MESTMÄCKER

1992 Kommentar zum Kartellgesetz, Munich.

INSTITUTO LIBERTAD Y DEMOCRACIA (ILD)

1989 La ley antimonopolio, Lima.

JOECKS, Wolfgang

1992 «Zur Schadensfeststellung beim Submissionsbetrug», en Wistra, p. 247.

MAAS, Noel

1980-B «El dumping: una forma importada de monopolio», en $L a$ Ley, Buenos Aires, p. 944 ss.

MALAMUD GOTI, Jaime

1984 Derecho penal de la competencia, Buenos Aires.

MOLSBERGER, Josef

1976 «Wirtschaftskriminalität und Wirtschaftsordnungen», en Festgabe für Alfred Müller-Armack, Colonia.

\section{NATIONS UNIES}

1974 Effets des societés multinationales sur le developpment et sur les relations internationales, New York.

OECD

1977 Restrictive Business Practices of Multinational Enterprises, Paris.

ORTUZAR LATAPIAT, Waldo

1989-I «El Derecho de la competencia», en Revista de Derecho y Jurisprudencia y Gaceta de los Tribunales, p.17 ss.

OTAMENDI, Jorge

1982-D «Criterios de la Comisión Nacional de Defensa de la Competencia», en La Ley, Buenos Aires, p 756 ss. 
REVISTA DE DERECHO Y JURISPRUDENCIA Y GACETA DE LOS TRIBUNALES (RDJyGT)

Sección sexta, Editorial Jurídica de Chile, Santiago de Chile.

RIGHI, Esteban

1991 Derecho penal económico comparado, Madrid.

RITTNER, Fritz

1989 Wettbewerbs- und Kartellrecht, Heidelberg.

ROHNKE, Christian

1987 Verhaltenskontrolle multinationaler Unternehmen durch extraterritoriale Anwendung nationalen Rechts und internationale Richtlinien, Munich.

SOLSONA, Enrique

1991-B «Dos leyes para la protección penal del consumidor. Abastecimiento y competencia», en La Ley, p. 794 ss.

TIEDEMAN, Klaus

1972 Welche strafrechtlichen Mittel empfehlen sich für eine wirksamere Bekämpfung der Wirtschaftskriminalität?, Munich.

1976-A Kartellrechtsverstöße und Strafrecht, Colonia.

1976-B Wirtschaftsstrafrecht und Wirtschaftskriminalität, Hamburgo.

1978-A «Derecho sobre los monopolios y Derecho penal del monopolio», en La reforma penal en los países en desarrollo, Universidad Nacional Autónoma de México (editor), México, p. 260 ss.

1978-B Wirtschaftskriminalität und Wirtschaftsstrafrecht in den USA und in der BRD, Tübingen.

1980 «Delinquenzverhalten und Machtmißbrauch multinationaler Unternehmen», en Multinationaler Unternehmen und Strafrecht, Klaus Tiedemann (editor), Colonia, p. 3 ss.

1985 Poder económico y delito, Barcelona.

1989 «Die Ahndung der Wettbewerbsdelikte in der Europäischen Wirtschaftsgemeinschaft», en Libro homenaje al pro- 
fesor Antonio Beristain, Instituto Vasco de Criminología, San Sebastían.

1990 Der Strafschutz der Finanzinteressen der Europäischen Gemeinschaft, NJW, p. 2226 ss.

1992 Lecciones de Derecho penal económico, Barcelona.

WARSCHAVER, Eduardo

1982 «Castigar a las trasnacionales: un ensayo de futurología en política criminal», en Doctrina Penal, Buenos Aires, p. 111 ss.

ZAFFARONI, Eugenio

«Criminalidad y desarrollo en Latinoamérica», en ILANUD, N. ${ }^{\text {os }} 13-14$, año 5, San José de Costa Rica. 